\title{
PROCESSOS FLUVIOMARINHOS ASSOCIADOS À FORMAÇÃO DA ILHA RASA, SUL DA BAÍA DE MARAPATÁ, NORDESTE DO PARÁ, BRASIL
}

\author{
Fluviomarine processes associated with the genesis of \\ Rasa island, south of Marapatá Bay, northeastern Pará, Brazil
}

\author{
Samuel Rodrigues Ribeiro', Roberto Célio Valadão² \\ 1 Programa de Pós-Graduação em Geografia, bolsista da Capes, Laboratório de Paleontologia e \\ Macroevolução, Instituto de Geociências, Universidade Federal de Minas Gerais. \\ E-mail:ribeiro.samr@hotmail.com \\ 2 Departamento de Geografia, Instituto de Geociências, Universidade Federal de Minas Gerais. \\ E-mail: valadaobh@gmail.com
}

\begin{abstract}
RESUMO
As ilhas assumem expressivo destaque na paisagem estuarina paraense; contudo, a maior parte delas apresenta gênese não claramente definida. A fim de investigar os fatores de formação da ilha Rasa, situada na foz do rio Tocantins, estuário do rio Pará, o presente trabalho se apoia em feições sedimentares identificadas em um testemunho de sedimento coletado no interior da ilha. Neste trabalho, a integração faciológica e a interpretação de seus ambientes deposicionais, em associação aos eventos climáticos reportados para a região, subsidiaram a proposição de modelo morfogenético. O modelo aqui proposto sugere que a ilha Rasa possui idade tardio-holocênica e consistia, incialmente, de barras arenosas que evoluíram sob o efeito de processos fluviais, inerentes à rede de drenagem e marinhos, articulados às mudanças no clima e nível do mar. Esses processos afetaram o suprimento de sedimento e a distribuição da cobertura vegetal, influenciando a configuração do setor estuarino e contribuindo para a formação de ilhas proximais.
\end{abstract}

Palavras-chave: barra arenosa, estuário, nível relativo do mar, ambiente sedimentar, rio Tocantins. 


\begin{abstract}
The islands take on significant prominence in the estuarine landscape of Pará State, although most of them present unclearly defined genesis. In order to investigate the formation factors of Rasa Island, located at the mouth of Tocantins, estuary of the Para River, the present work is based on sedimentary features, identified in the sediment core taken by a Russian Sampler from a fluviomarine plain. In this study, the faciologic analysis and interpretation of sedimentary environments, in association with climatic events reported to the region, supported the proposition of a morphogenetic model. The model proposed here suggests that Rasa Island has late Holocene age and consisted of sandy bars that evolved under the effect of fluvial processes, inherent to the drainage basin, and marire processes related to sea level changes and climate changes. These processes affected the sediment supply and distribution of vegetation cover, influencing the estuarine sector and contributing to the formation of proximal islands.
\end{abstract}

Keywords: sandy bars, estuary, relative sea level, sedimentary environment, Tocantins river.

\title{
INTRODUÇÃO
}

As ilhas compreendem as feições emersas dos ambientes aquáticos. Segundo Brice (1964), elas se diferem das barras devido à estabilização dos materiais e à presença de vegetação. Os processos envolvidos na formação insular determinam sua origem, podendo resultar da atividade deposicional, tectônica e vulcânica.

No caso de ilhas cuja origem esteja associada à dinâmica deposicional, a morfogênese envolve comumente mecanismos de erosão, transporte e deposição de material siliciclástico proveniente da área fonte, de modo que a investigação de seus processos originários perpassa pela identificação da organização sedimentológica e arquitetural de seu registro sedimentar, a qual viabiliza a identificação de fácies e dos processos responsáveis pela sua deposição. A análise da sucessão vertical de fácies e seus elementos arquiteturais são fundamentais para a sua reconstituição paleoambiental (Allen, 1965; Miall, 1978).

A partir da aplicação de métodos sedimentológicos e estratigráficos, Barbosa (2015) reconheceu os fatores que contribuíram para a formação de depósitos quaternários no Arquipélago de Anavilhanas, baixo curso do rio Negro, no Amazonas. Leli (2015), mediante utilização de métodos semelhantes àqueles empregados por Barbosa (2015), investigou a evolução geomorfológica do conjunto de ilhas no alto rio Paraná, Sul do Brasil, concluindo pela efetividade de processos intra e extracanais na gênese das ilhas investigadas. Nos exemplos mencionados, os objetos estudados situam-se em trechos de domínio fluvial, com assinaturas de processos genético-específicos deste ambiente. No caso de ilhas localizadas em domínio estuarino, estas passam a incorporar forçantes bimodais - fluvial e marinha -, que interagem combinando mecanismos diferenciados, tendo em vista a ocorrência do fluxo e refluxo das marés que invertem a energia e a densidade hídrica, controlando o local de aporte sedimentar e, consequentemente, a configuração do modelado insular.

Entre a complexidade dos ambientes costeiros, o ambiente estuarino é aquele que, fundamentalmente, assume caráter transicional. Em razão desse caráter, apresenta alto dinamismo nos parâmetros físico-químicos devido à constante resposta do estuário aos pro- 
cessos naturais gerados pela variação vertical do nível do mar, pela descarga fluvial, pela flutuação nos gradientes de salinidade (densidade) resultante da diluição da água salgada, pela circulação na plataforma continental e pela ação dos ventos (Miranda; Castro Filho \& Kjerfve, 2002). Definido como a região de mistura da água doce do rio com a salgada do oceano, alguns conceitos consideram como estuário até a secção a montante da zona de mistura, onde a influência do rio é maior em relação às marés (Pritchard, 1967).

O estuário paraense constitui amplo corpo hídrico formado pelo rio Pará, que recebe a contribuição do Tocantins, Maratauíra-Capim e Guamá-Acará, rios de maior hierarquia e volume de água. O regime de marés semidiurnas exerce grande influência na morfodinâmica local, fazendo surgir zonas particulares de erosão, transporte e sedimentação. Muito provavelmente na sua porção insular está também presente a interação desses processos.

Devido às características das ilhas que integram o estuário paraense, notadamente suas distribuição e dimensão espaciais, com ordem de grandeza que varia de metros a milhares de quilômetros, elas ocupam destaque na paisagem estuarina. Genericamente, essas ilhas são agrupadas em Formação aluvial (Barbosa; Rennó \& Franco, 1974), possivelmente por compreenderem a recente história da geomorfologia costeira, com suprimento e evolução sedimentar associados ao ambiente aquático.

Apesar de expressivas junto à interface litorânea e nos setores mais internos, grande parte das ilhas do estuário investigado não foi, até então, objeto de estudo voltado à sua morfogênese. Nesse contexto é que se insere este trabalho, cujo objetivo é investigar os processos que respondem pela formação da ilha Rasa, no Baixo Tocantins, ao sul da Baía de Marapatá, nordeste do Pará, mediante integração de dados geomorfológicos e a análise do registro estratigráfico de seus ambientes deposicionais.

\section{MATERIAIS E MÉTODOS}

A área de estudo localiza-se na porção oeste do município de Igarapé-Miri, baixo curso do Tocantins, sul da Baía de Marapatá (Figura 1-b), Zona Costeira Paraense (ZCP), onde é afetada pelo regime de mesomaré semidiurna, com amplitude máxima de 3,42 m durante a sizígia (DHN, 2019). Nessa área, a velocidade média do rio Tocantins é de $0,46 \mathrm{~m} / \mathrm{s}$ na vazante e $-0,4 \mathrm{~m} / \mathrm{s}$ na enchente durante a estação seca, e de $0,52 \mathrm{~m} / \mathrm{s}$ na vazante e $-0,54$ na enchente durante a estação chuvosa (Costa, 2014). O clima é tropical quente e úmido, tipo Am da classificação de Koppen e a temperatura média anual de $\sim 27^{\circ} \mathrm{C}$. A umidade relativa do ar apresenta-se superior a $80 \%$ e a precipitação pluviométrica supera $2.000 \mathrm{~mm}$ por ano, com a estação chuvosa concentrada entre os meses de dezembro e maio (Fapespa, 2016).

A ilha Rasa está inserida na unidade da Planície Amazônica, altimetria $<5$ m e declividade inferior a 2\% (Furtado \& Ponte, 2013). Ela é recoberta pela Floresta Ombrófila Densa Aluvial, constituída, principalmente, de Euterpe oleracea Mart., Pterocarpus amazonicus Huber, Virola surinamensis Cham. e Mauritia flexuosa L. Nos trechos marginais, ocupados por depósitos lamosos, topograficamente mais baixos, Formações pioneiras dominam a paisagem com a presença de Rhizophora, formando uma estreita franja de manguezal, intercalada por sub-bosque de Montrichardia sp. em consórcio com Machaerium lunatum.

O trabalho de campo foi realizado para a coleta do testemunho de sedimento (ISR) em janeiro de 2019. O testemunho foi extraído da planície fluviomarinha recoberta por vegetação arbórea através de trado russo. De coordenadas $1^{\circ} 81^{\prime} 75,7^{\prime \prime} \mathrm{S}$ e $49^{\circ} 14^{\prime} 73,5^{\prime \prime} \mathrm{W}$, o ISR tem profundidade de $410 \mathrm{~cm}$, ponto de sondagem distante aproximadamente $280 \mathrm{~m}$ 
da margem leste (Figura 1-a). A determinação do local de amostragem foi baseada na possibilidade de acesso, associada à maior elevação em relação aos demais níveis altimétricos verificados na ilha. Durante o campo, foi realizado também o levantamento da cobertura vegetal, descrição das feições morfológicas e coleta de coordenadas geográficas com uso de GPS (Global Positioning System). O ISR não foi nivelado devido à ausência de dados topográficos.

Para a descrição e o modelamento de fácies, neste trabalho foi adotado o método de Walker (1992). O modelamento de fácies consiste na individualização e descrição das fácies para caracterizar sua composição, geometria, textura, estruturas sedimentares e eventual conteúdo fossilífero. A cor incluída na descrição de fáceis foi determinada segundo a Carta de Munsell. As fácies sedimentares foram codificadas seguindo Miall (1978) e agrupadas em associações de fácies. A análise de sucessão vertical de fácies e de seus elementos arquiteturais é de fundamental importância para a reconstituição paleoambiental (Reading, 1996).

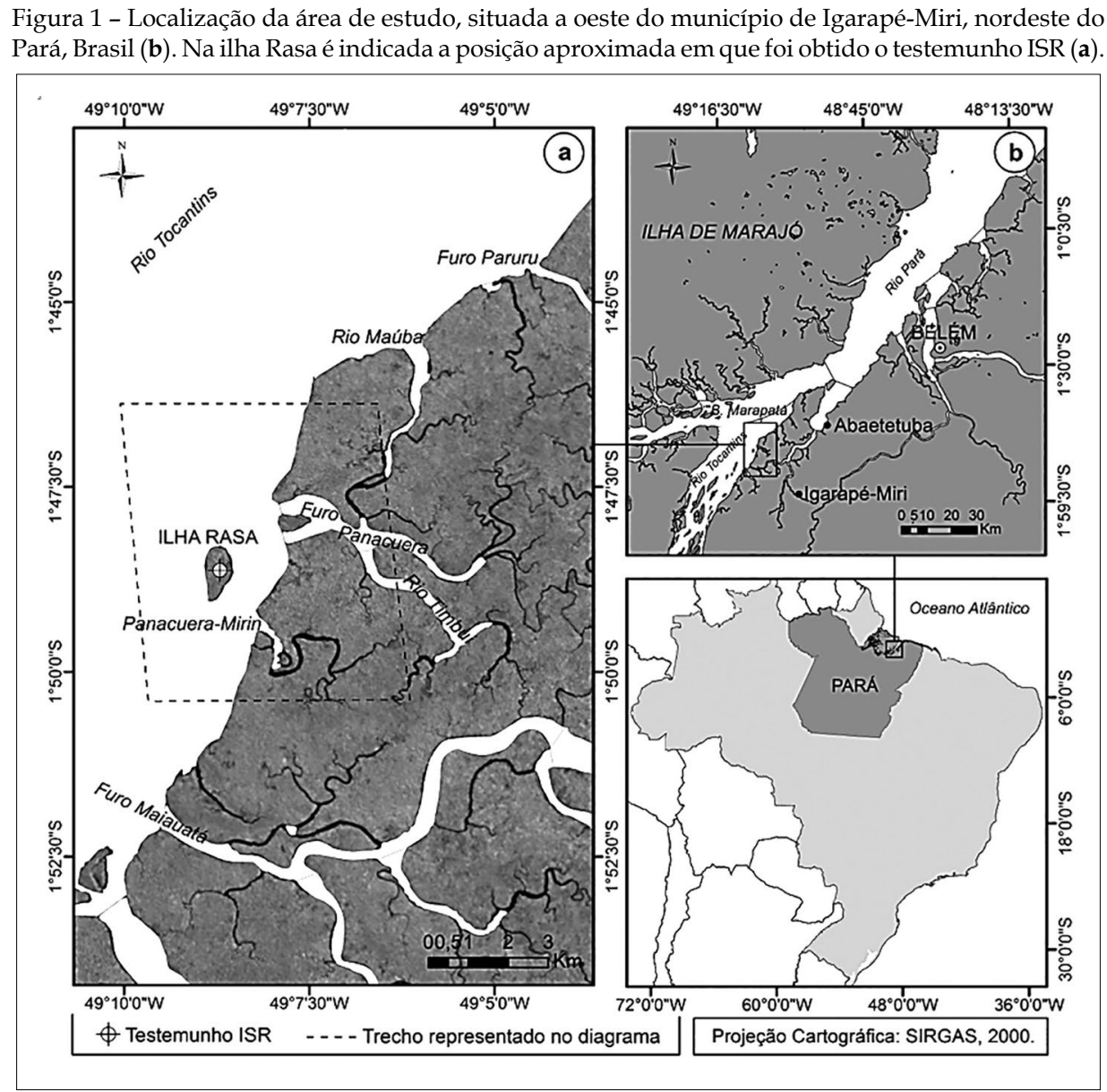

\section{RESULTADOS E DISCUSSÕES}

A ilha Rasa é constituída por áreas de acumulação lamosa e trechos marginais de deposição arenosa. Ela apresenta baixo gradiente topográfico, favorável às inundações periódicas. A variação dos ciclos de marés semidiurnas responde ao desenvolvimento dos distintos ambientes deposicionais atuais. 
O testemunho ISR coletado na planície exibe maior presença de lama, com a coloração que varia de acinzentado a preto acinzentado, seguido da areia, de coloração cinza oliva e marrom acinzentado, com textura variando de fina a média. Na maior parte da sucessão sedimentar, intervalo de $250 \mathrm{~cm}$ a $0 \mathrm{~cm}$, verificou-se a presença de matéria orgânica e restos de planta, principalmente raízes e folhas, conforme representado na Figura 2. Observe, nessa mesma figura, que o perfil estratigráfico apresenta decréscimo no tamanho dos grãos da base até a profundidade de $18 \mathrm{~cm}$, caracterizando uma sucessão granodecrescente ascendente. A partir da análise das estruturas sedimentares, foram definidas duas associações de fácies: (A) Barra de canal fluvial e (B) Planície fluviomarinha (Figura 2).

A associação de fácies A ocorre ao longo do intervalo 410 a $260 \mathrm{~cm}$ e é caracterizada, principalmente, pela presença de areia, granulometria variando de fina a média. Essa associação consiste das fácies areia maciça $(\mathrm{Sm})$, intervalo 410 a 319 cm, acamamento heterolítico flaser (Hf) entre 319 e 300 cm e acamamento com estratificação heterolítica inclinada (IHS), intervalo de 300 a $260 \mathrm{~cm}$ (Figura 2).

A associação de fácies B, por sua vez, corresponde ao depósito mais expressivo do ISR, compreendido entre 260 e $0 \mathrm{~cm}$. Essa sucessão é caracterizada, principalmente, pela presença de lama, além de fragmentos vegetais incorporados ao seu conteúdo (Figura 2). A associação de fácies B é constituída pelas fácies acamamento heterolítico lenticular (Hl), compreendida entre 260 e $175 \mathrm{~cm}$ e 18 e $0 \mathrm{~cm}$ e lama maciça (Mm), intervalo de 175 a $18 \mathrm{~cm}$ (Figura 2). A integração desses dados e sua associação ao passado climático regional fornecem elementos à reconstituição paleoambiental e auxiliam no entendimento dos processos morfogenéticos ocorridos na ilha Rasa.

Figura 2 - Perfil estratigráfico do testemunho ISR, obtido na ilha Rasa que integra o sistema estuarino do rio Tocantins (Pará, Brasil)

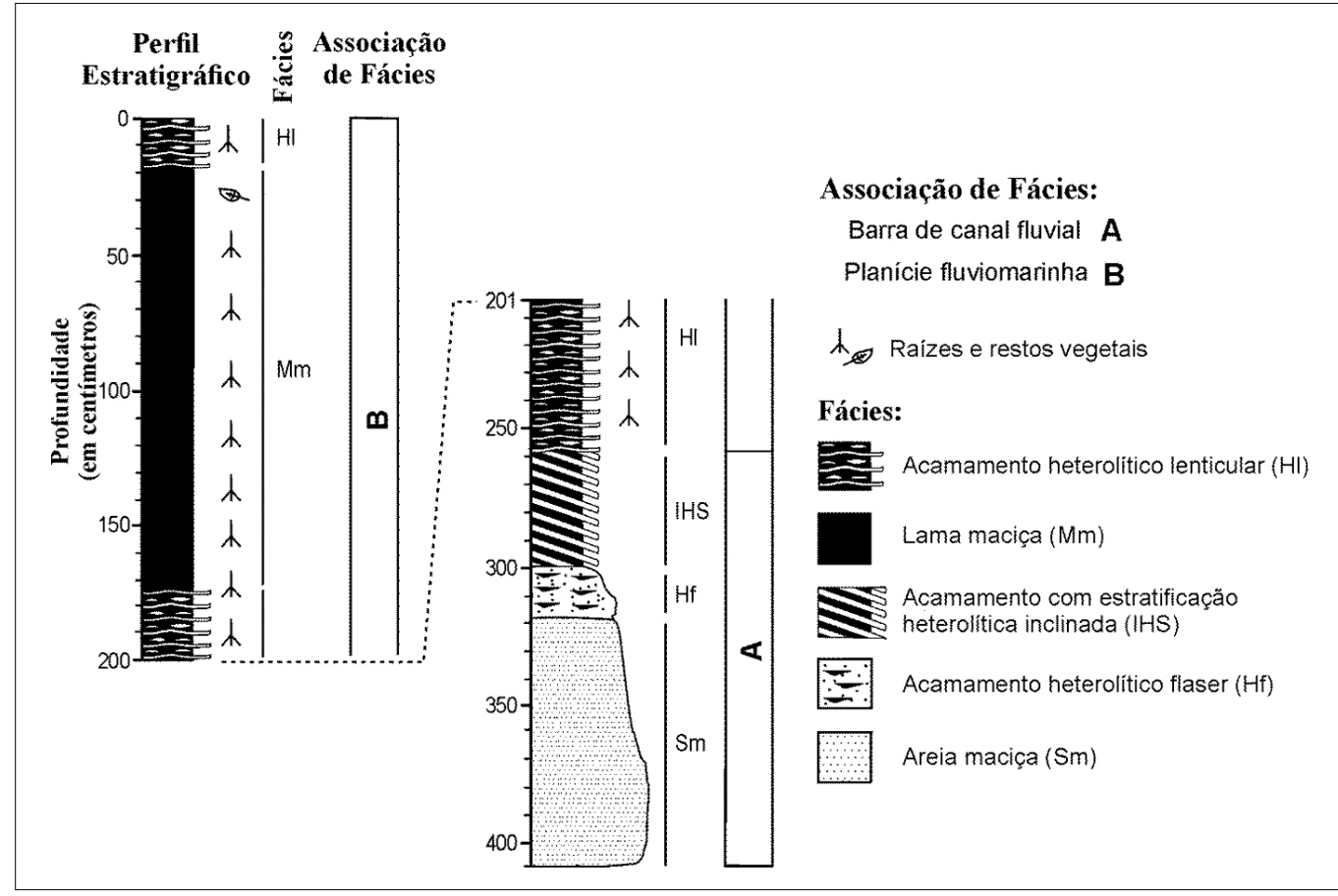

A passagem do Pleistoceno para o Holoceno Inicial foi marcada pelo nível do mar abaixo do atual devido ao Último Máximo Glacial (Maslin; Vilela; Mikkelsen \& Grootes, 2005). Esse evento regressivo enfraqueceu a influência marinha na configuração da geo- 
morfologia costeira, de modo que os processos fluviais passaram a dominar a arquitetura morfológica deste setor, em detrimento aos processos marinhos.

No rio Tocantins, segmento de montante, a incisão e o aprofundamento de cursos fluviais conectados à sua rede de drenagem foram intensificados, leitos rasos emersos e depósitos transgressivos expostos e desmontados pela tomada de erosão, enquanto barras eram formadas a jusante. O nível do mar baixo que propiciou maior erosão foi responsável pelo suprimento de sedimentos para o desenvolvimento e expansão das barras fluviais. É provável que neste período, o trecho que compreende a atual ilha Rasa consistia de barras formadas principalmente por areia (Figura 3-i), como sugere a fácies Areia maciça (Sm) da associação de fácies $\mathbf{A}$, na base do testemunho. A fácies areia maciça (Sm) revela deposição rápida em ambiente de alta energia (Figura 2).

A montante da área investigada é provável que a fase fluvial tenha contribuído para a formação de sistemas de barras que tardiamente evoluíram para sistema de ilhas, processo análogo ao da ilha Rasa. Esse sistema de ilhas apresenta alinhamento longitudinal compatível com o curso moderno do rio Tocantins (Figura 1-b), o que sugere idade não superior ao Holoceno. Além disso, em tributários que drenam para o Tocantins e têm seus cursos perpendiculares a este rio, a descida do nível do mar deve ter condicionado a formação de aparelhos deltaicos junto às suas desembocaduras (Figura 3-i). As ilhas modernas na foz do sistema Panacuera-Timbuí e do Panacuera-Miri podem ser elementos morfológicos documentando a fase regressiva. A paisagem ecológica, por sua vez, deve ter sido dominada por vegetação de água doce (Figura 3-i).

O estágio seguinte foi marcado pelo aumento do nível do mar pós-glacial durante o Holoceno Médio (Behling \& Costa, 2001; Vedel; Behling; Cohen \& Lara, 2006). Nesse período, o baixo curso do Tocantins deve ter evoluído da fase fluvial para estuarina e os processos marinhos e a intrusão salina passaram a exercer controle na geomorfologia e na ecologia local, respectivamente.

É possível que o nível do mar tenha atingido a elevação máxima em $~ 5.000$ anos A.P., encobrindo barras e depósitos de leitos e formando uma densa e complexa rede de canais afogados, os quais inundaram a planície e os setores de topografia inferior. No ambiente ecológico, a vegetação de água doce deve ter sido espacialmente reduzida, enquanto uma franja de manguezal se desenvolveu (Figura 3-ii) em consequência à incursão marinha (e.g., Cohen et al., 2012). Parte dessa franja constituída de mangue se mantém na paisagem atual.

Por outro lado, a dinâmica estuarina resultou na migração lateral de canais no setor insular. A fáceis acamamento com estratificação heterolítica inclinada (IHS), depositada por ritmitos de energia e influenciada por maré (vazante-enchente e estofo de águas paradas), relaciona-se à dinâmica desses cursos fluviais (Figura 2). Em decorrência da migração de canais, um lago começa a ser formado à medida que o nível do mar regredia (Figura 3-iii). Embora se admitam curtos eventos de subida do nível relativo do nível do mar (NRM) durante o Holoceno Superior (e.g., 3.630 anos cal. A.P. [Behling \& Costa, 2001]), as curvas de descida seguintes deslocaram o NRM para o nível moderno.

Essa redução do nível do mar modificou o ambiente sedimentar, conforme retratado pela associação de fáceis Planície Fluviomarinha (B) do perfil estratigráfico (Figura 2). A fácies acamamento heterolítico lenticular $(\mathrm{Hl})$, na base desta associação, sugere que o lago formado mantinha relativa conexão com o rio - laguna -, possivelmente através do ciclo de 
marés. Posteriormente, processos intracanais levaram ao abandono e à completa individualização da feição lacustrina por volta de $~ 3.500$ anos A.P., quando a descida do NRM se fez mais pronunciada (Figura 3- terceiro estágio evolutivo).

A redução de competência das correntes e o baixo nível de energia possibilitaram que o material em suspensão, constituído principalmente por fração fina (silte e argila), fosse depositado. Assim, a predominância de aquiescência no ambiente lacustre resultou na formação da mais espessa sucessão sedimentar (154 cm - fácies lama maciça [Mm]) do ISR. A colmatação é apoiada também pela presença de raízes e folhas, uma vez que os depósitos lamosos devem ter sido tomados por espécies higrófilas dos estratos fisionômicos herbáceo e arbustivo (Figura 2).

Figura 3 - Processo de formação da ilha Rasa (foz do Tocantins, estuário do rio Pará, estado do Pará) considerando dados estratigráficos, processos fluviais e variações do nível o mar - estágios (i) a (iv).

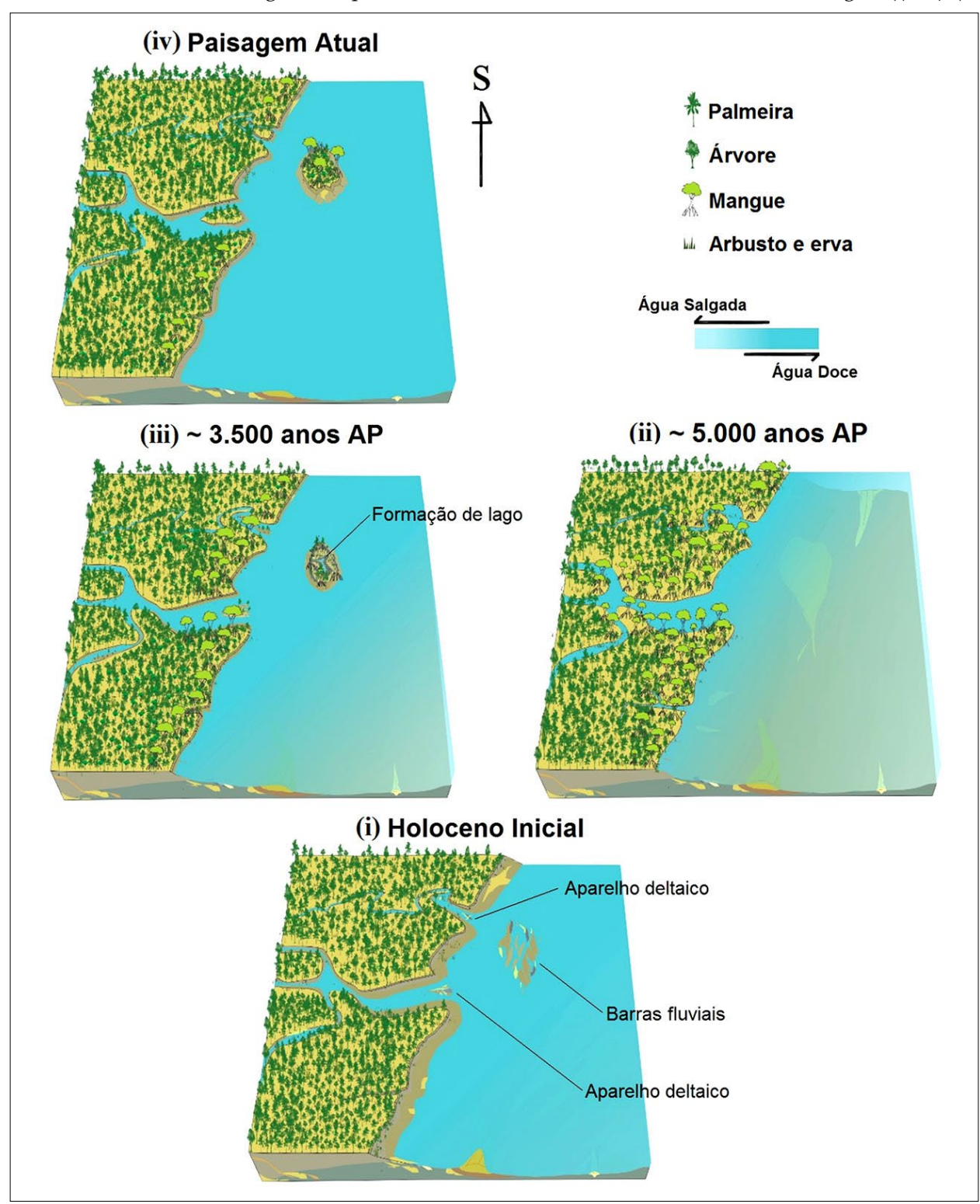

O estágio final de formação da ilha Rasa está associado ao nível do mar estabilizado e à expansão do tecido ecológico no substrato insular (Figura 3-iv). A vegetação inferior foi 
gradualmente substituída por grupos botânicos de fisionomia arbórea que passaram a prosperar na ilha, constituídos por gêneros pioneiros, os quais cresceram consorciados nas cotas mais baixas (Rhizophora e Montrichardia sp.), enquanto a floresta aluvial, representada principalmente por espécies de Pterocarpus amazonicus Huber, Virola surinamensis Cham. e Euterpe oleracea Mart., recobriu os setores mais elevados. Na área amostrada, por sua vez, a hidrodinâmica promoveu um novo aporte de sedimento lamoso, com vazões periódicas de areia, exibido pela fácies acamamento heterolítico lenticular $(\mathrm{Hl})$, próximo ao topo do testemunho (Figura 2). Esses processos influenciaram a morfogênese insular e contribuíram para a estruturação de sua paisagem moderna.

\section{CONSIDERAÇÕES FINAIS}

Este trabalho, ao combinar feições sedimentares do testemunho ISR coletado na planície da ilha Rasa, na foz do rio Tocantins, nordeste do Pará, revelou um ambiente deposicional influenciado por processos fluviais e marinhos. As fácies identificadas permitiram a distinção de duas associações de fácies: Barra de canal fluvial (A) e Planície fluviomarinha (B).

Com base na interpretação dos ambientes deposicionais em associação aos eventos climáticos documentados na região, um modelo morfogenético foi elaborado e composto de quatro estágios. No primeiro, a ilha Rasa consistia em barras fluviais formadas durante a regressão marinha ocorrida entre o Pleistoceno Terminal e início do Holoceno. O estágio seguinte ( 5.000 anos A.P.) é marcado pela elevação do nível do mar pós-glacial. A subida do nível do mar encobriu barras, depósitos de leito, comandou a migração lateral de canais, afogou rios e planície e afetou significativamente o ambiente ecológico. O terceiro estágio relaciona-se com a redução do nível do mar, o qual favoreceu a formação de um lago por volta de $\sim 3.500$ anos A.P. O sistema lacustre possibilitou a deposição do material fino em suspensão, resultando na mais espessa sucessão sedimentar. A colmatação é suportada também pela presença de fragmentos vegetais no conteúdo dessa sucessão. Finalmente, com a estabilização do nível do mar, seguida de acreção sedimentar influenciada pela hidrodinâmica, os depósitos foram recobertos por vegetação de fisionomia predominantemente arbórea e a ilha passou a exibir a configuração morfológica moderna.

Agradecimentos - À Coordenação de Aperfeiçoamento de Pessoal de Nível Superior (Capes), pela concessão de bolsa de doutorado ao primeiro autor, e ao Programa de Pós-Graduação em Geografia (PPG-IGC/UFMG), pelo auxílio financeiro para a realização do trabalho de campo. Os autores agradecem ainda ao Laboratório de Paleontologia e Macroevolução (CPMTC-IGC/UFMG), pelo equipamento de sondagem, a João Moraes e Raimundo Ribeiro, pelo apoio técnico e suporte na logística durante a execução do campo, bem como ao senhor Edilson Nahun, que gentilmente permitiu o acesso e a coleta na ilha Rasa.

\section{REFERÊNCIAS BIBLIOGRÁFICAS}

Allen, J.R.L. A review of the origin and characteristics of recent alluvial sediments. Sedimentology, v. 5, n. 2, p. 89-191, 1965.

Barbosa, G.V.; Rennó, C.V. \& Franco, E.M.S. Geomorfologia da Folha SA-22 Belém, in Brasil. DNPM. Folha SA.22 Belém: geologia, geomorfologia, solos, vegetação, uso potencial da terra. Rio de Janeiro, 1974. 
Barbosa, R.O. Estudos sedimentológicos e estratigráficos dos depósitos sedimentares quaternários do Arquipélago de Anavilhanas, município de Novo Airão. 2015. Dissertação de mestrado, Programa de Pós-Graduação em Geociências, Universidade Federal do Amazonas, 113 p., Manaus, 2015.

Behling, H. \& Costa, M.L. Holocene vegetational and coastal environmental changes from the Lago Crispim record in northeastern Pará state, eastern Amazonia. Review of Paleobotany and Palynology, v. 114, n. 3-4, p. 145-155, 2001.

Brice, J.C. Channel patterns and terraces of the Loup Rivers in Nebraska. US Geol. Surv. Prof. Pap., n. 422-D, p. 1-41,1964.

Cohen, M.C.L.; Pessenda, L.C.R.; Behling, H.; Rossetti, D.F.; França, M.C.; Guimarães, J.T.F.; Friaes, Y.S. \& Smith, C.B. Holocene palaeoenvironmental history of the Amazonian mangrove belt. Quaternary Science Reviews, v. 55, p. 50-58, 2012.

Costa, M.S. Aporte hídrico do material particulado e em suspensão para a Baía do Marajó: contribuição dos rios Jacaré Grande, Pará e Tocantins. 2014. Dissertação de mestrado, Programa de Pós-Graduação em Geologia e Geoquímica, Universidade Federal do Pará, 71 p., Belém, 2014.

Diretoria de Hidrografia e Navegação. DHN. 2019. Tábua das Marés. Marinha do Brasil. Disponível: http://www.mar.mil.br. Acesso: 5 jan. 2019.

Fundação Amazônia de Amparo a Estudos e Pesquisas. FAPESPA. Estatísticas municipais paraenses: Igarapé-Miri. Diretoria de Estatística e de Tecnologia e Gestão da Informação. Belém, 2016.

Furtado, A.M.M. \& Ponte, F.C. Mapeamento de unidades de relevo do estado do Pará. Revista GeoAmazônia, v. 1, n. 2, p. 56-67, 2013.

Leli, I.T. Gênese, evolução e geomorfologia das ilhas e planície de inundação do alto rio Paraná, Brasil. 2015. Tese de doutorado, Programa de Pós-Graduação em Geociências e Meio Ambiente, Universidade Estadual Paulista, 123 p., São Paulo, 2015.

Maslin, M.A.; Vilela, C.; Mikkelsen, N. \& Grootes, P. Causation of the Quaternary catastrophic failures of the Amazon Fan deduced from stratigraphy and benthic foraminiferal assemblages. Quaternary Science Reviews, v. 24, n. 92, p. 2180-2193, 2005.

Miall, A.D. Facies types and vertical profile models in braided river deposits: a summary, p. 597-604, in Miall, A.D. (ed.), Fluvial Sedimentology. Canadian Society of Petroleum Geologists Memoir 5, 859 p., Calgary, 1978.

Miranda, L.B.; Castro Filho, B.M. de \& Kjerfve, B. Princípios de oceanografia física de estuários. São Paulo: Editora da Universidade de São Paulo, 424 p., 2002.

Pritchard, D.W. What is an estuary? Physical viewpoint, p. 3-5, in Lauff, G.H. (ed.), Estuaries. American Association for the Advancement of Science Publication, 757 p., Washington DC,1967.

Reading, H.G. Sedimentary environments and facies. Oxford: Blackwell Scientific Publications, 576 p., 1996.

Vedel, V.; Behling, H.; Cohen, M.C.L. \& Lara, R. Holocene mangrove dynamics and sealevel changes in northern Brazil, inferences from the Taperebal core in northeastern Pará State. Vegetation History and Archaeobotany, v. 15, n. 2, p. 115-123, 2006. 
Walker, R.G. Facies, facies models and modern stratigrahic concepts, p. 1-14, in Walker, R.G. \& James, N.P. (eds.). Facies models: response to sea level change. Ontario: Geological Association of Canada, 409 p., 1992. 